\title{
The risks and legal advice of NFC payment
}

\author{
Xiaoyu Zou, a \\ ${ }^{1}$ School of Yantai University, Yantai 264005, China. \\ a505772196@qq.com
}

Key words: mobile payment; NFC payment; risks; precautions; legal advice

\begin{abstract}
Based on the environment of mobile e-commerce, the issue of the risks of mobile payment arouses wide attention. But 《The Management Approaches of Online Payment of Non-bank Payment Institutions》d does not apply to NFC payment. Aiming at the problems of NFC payment, including security risks of passive NFC Tags, information disclosure risks in the implementation environment and security risks of mobile terminals. Supervision as main measures, comprehensive using of constraints, authorization and certification ,and regulating information utilization and protection are proposed, in order to promote the healthy development of NFC payment and achieve continuous innovation of mobile e-commerce .
\end{abstract}

\section{Application and legal norms of NFC payment}

NFC payment uses the technology of Near Field Communication, no need for mobile network, no need to touch each other. And NFC RF channel can be related to the POS cash register and other local communications equipment to achieve payment.

NFC payment that can realize offline payment is the measure of banks to resist the impact of the online payment. NFC payment achieves consumption without bank card but mobile wallet .So ,it provides convenient conditions for payment service, balance inquiries, medical service and other functions.

\subsection{Application of NFC payment}

At present, the application scale and scenarios of NFC payment are narrow. And its market share in the mobile payment market is far less than the third-party payments. But all the same, NFC payment still develops rapidly relied on its own advantages and policy support .

(1)Unique advantages of NFC payment in performance

a. The process of NFC payment is more simple and convenient. Users just need to bind the bank card information and NFC account together in the mobile terminal, and then ,the mobile wallet is formed. At the time of payment, as long as the mobile terminal and other credit card equipment ,such as POS machines, maintain a distance of $10 \mathrm{~cm}$, you can complete the transaction within 0.1 seconds.

b. It doesn't need the intervention of the third-party. NFC payment makes use of the Quartet model(UnionPay, card issuers, acquirers, users).It means that the payment will be carried out by UnionPay ,and then, it will transfer from the card issuer to acquirers. The entire process of payment doesn't need for third-party as an intermediary to participate in payment activities.

c. Mobile networks and power supply are not necessary. On the one hand ,NFC payment terminal makes use of RFID technology to read the NFC tag, and then, the antenna will be used to transfer the transaction information to the bank processing system for data processing. On the other hand, even when the mobile terminal equipment were turned off or no electricity, electronic cash offline payment is still able to achieve through the RF domain power supply.

(2) Excellent policy environment on NFC payment

a. Central bank creates a good environment for the application of NFC payment. The central bank has issued 《Guiding Opinions of the People's Bank of China on the Development of Mobile

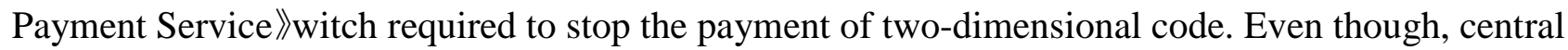
bank recognized the payment status of two-dimensional code through 《Bar code payment service standard》,this creates a huge space for the survival and growth of NFC payments. 
b. The space of NFC payment is broad for growth. The central bank strengthen the standards and management about third party mobile payment through 《The Management Approaches of Online Payment of Non-bank Payment Institutions》.But, it does not apply to NFC payment. This means that the NFC payment is not yet belong to the management scope of financial IC card, nor is classified in the network payment. So ,in conclusion ,the development space of NFC payment is very broad.

In the power of the policy, the application scenarios of NFC payment are more vivid and diverse .And the scale of the application of NFC payment is also expanded .

\subsection{Legal norms on NFC payment}

NFC payment management is in a dilemma situation because of its own special properties. A view claims that it belongs to the scope of financial IC card management, and should be applicable to China's financial IC card management regulations and norms. The theoretical basis is that NFC payment ,as a method which achieves payment cross industry and channel ,is the innovation and virtualization of financial IC card. Another view is that because of the near field communication, NFC payment should belong to the application of mobile payments under the online scene. So, it is recommended that NFC payment should be subject to the regulations of the network payment regulations.

At present, the management of NFC payment is still in the blank stage. The attitude of central bank to pay NFC is innovative, open and compatible. And the requirement just is collaborative innovation of the industrial chain. But major banks are all actively involved in the construction of NFC application scenarios and market promotion in order to compete for the mobile payment market. In spite of this, the risk of NFC payment still can not be ignored.

\section{The security risk of NFC payment}

Mobile payment brings users vivid and convenient payment experience, but its rapid development trend also allows users to generate a lot of concerns. Research report prepared by the Payment \& Clearing Association of China displays that $70.6 \%$ of mobile payment users are worried about the presence of mobile payment security risks in 2015. Among them, $73 \%$ of the users have a big concern about personal privacy leak, and $62.8 \%$ of users are concerned about the security issues of the payment link.

As a way of mobile payments, there are obvious security risks on NFC payment . These risks specific performance in three aspects: the security risks of passive NFC tags, the information leakage risks of the implementation environment, the operation security risks of mobile terminal and so on.

\subsection{The security risks of passive NFC tags}

Passive NFC tag is the carrier of the data. And it is necessary of the achievement of the read and payment functions of NFC payment. Passive NFC tags can be read, written and rewritten repeatedly, but each label can just write one message at a time. When the NFC mobile terminal close to the tag, the tag data will be read.

At the first, the data of NFC tags are static so that it is easy to be stolen, be destroyed and be tampered. Once the middle man to steal information within the NFC tags, even if the information of payment is correct, the payment has long entered the illegal account. Because of the sensitivity and penetrate of NFC payment, reading the NFC tags is not restricted by the barrier. When the data in the NFC tags is destroyed or tampered with, the user maybe suffer economic losses when reading and payment due to wrong payment information.

Secondly, the NFC tag does not have a system of protection layer about security encryption. And then, the user maybe face the risk of fraud when using NFC payments.

Thirdly, NFC tags are the key process to achieve NFC payment, and there is great value of the data within the tag. The tag data users got is the only basis for payment, because there is no dynamic code. The greater the value of the data, the more likely to be stolen or tampered with, the more likely to cause fraud consequences. 


\subsection{The information leakage risks of the implementation environment}

At present, there are two models of execution environment of NFC payment . One mode is in the hardware configuration of the mobile terminal, setting up a trusted execution environment independent of the operating system. The realization of the model mainly depends on the manufacturer and the chip maker. Another model is to bind the NFC function with the SIM function of the 4G card. The realization of the model mainly depends on the operator. No matter what kind of model to take, NFC payment will face the risk of information leakage, because it has a strong dependence on the implementation of the environment.

(1)Mobile terminal equipment can be converted into an illegal POS. When the NFC mobile terminal near the bank chip card, the user's private information will be acquired, such as the card number, electronic wallet balance, part of the ID card and so on . After the information is stolen, the users are not only faced with the risk of counterfeit bank card stolen, but also face the risk of personal information being leaked.

(2) NFC payment information exists the risk of being intercepted. NFC payment achieves financial information exchange and personal information transfer in private communication way. However, the characteristics of non contact payment, as well as the characteristics of penetrating the metal, increase the risk of the interception of the payment information. Even if the metal protective sleeve can not protect the security of mutual information.

the security standards of the execution environment that NFC payment depends on are not uniform, and the extent of the protection of information is not consistent. The technical standard of the main body of the industry chain is not unified, resulting in the lack of protection of information security of the operating system, SIM card, and execution environment.

\subsection{The operation security risks of mobile terminal}

The operation security risks of mobile terminal of NFC payment can not be ignored. The main security risks include the following three aspects:

The security risks caused by mobile phone viruses and software viruses. NFC payment can not completely out of the operating system of the mobile terminal. When the software is hidden virus, or users mistakenly open phishing sites, the operating system will be virus. The mobile terminal completely manipulates by hacker, resulting in the security of NFC payment can not be guaranteed.

The payment vulnerabilities existed in Low end mobile devices. Currently on the market, many manufacturers of mobile devices see the function of NFC payment as marketing selling point, but some NFC payment function on low-end equipment is not perfect. When using the payment operation, the existence of the vulnerability can automatically file or operate the browser, or control the user's mobile devices in the case of users do not know.

For NFC payment, the mobile terminal brings a higher probability of security risks than the loss of information. Therefore, the control of the mobile terminal is relatively more important.

\section{Legal measures to guarantee the security of NFC payment}

In view of the current situation of China's NFC payment, there is no clear laws or regulations, no perfect legal supervision system. Many of the limitations of payment risks and legal defects will inevitably hinder the development of NFC payment and the prosperity of China's mobile payment market. Therefore, it is necessary, on the basis of analyzing the risk of NFC payment, to put forward relevant legal countermeasures and suggestions. Put forward these proposals in order to regulate the mobile payment market, and promote the healthy development of NFC payment.

\subsection{Supervision as the main way, guide as a supplementary way}

In order to provide a broad development space for NFC payment, and fully mobilize the enthusiasm and activity of the mobile payment market, the market mechanism must play a regulatory role. at the same time, the regulatory authorities should take regulatory measures, based on law and policy guide supplement. The necessity of supervision is to respect the laws of development of mobile payment market. The necessity of guiding is to give play to the long-term 
guiding role of law and policy, and to make up the deficiency of the short term market behavior of mobile payment:

First of all, the main purpose of regulation is to prevent the occurrence of a series of risks. In view of the characteristics of NFC payment, the regulatory authorities should create an open regulatory environment to prevent the generation of risk which based on the management of the bank card and mobile payment.

Secondly, the main content of the regulation is the behavior of the main bodies of the industry chain. For example: the manufacturers and chip factories of the NFC mobile terminal can not achieve a unified standard, and can not improve significantly the technology vulnerabilities. In addition, in the process of interest game, whether the behavior of the participants in the industry chain is against the legitimate interests of the users or against the law of competition in the market.

Third, the main way of supervision is the coordination and division of the regulatory authorities, in order to improve the level of supervision and management of NFC technology, capital security and information utilization.

Fourth, guidance should be based on the guidance and policy approaches. As rapidly changing of the mobile payment market, the guidance and policy approaches are more flexibility and timeliness, so they can make up the lag of the law. Only in this way, the risks of NFC payment can be more timely and effective responded.

Fifth, carefully guide should focus on the risks and problems of NFC payment . Based on the investigation and research, we should guide the industry self-regulation, guide the construction of infrastructure and payment environment, and guide the standardization of technical management.

\subsection{Specification, authentication and authorization should be used synthetically}

Regulation and restriction of NFC payment mean that the relevant legal issues related to NFC payment should be in clear and specific forms through the administrative organs and financial management institutions, especially in statutory provisions. The specific contents of the specification includes the following points:

Clear technical standards for NFC payment. The diversified technical standards for NFC payment should be avoided. Technical standards should be unified, clear, and eliminate the low end of technology. At the same time, it should be in the development of technical standards. We should learn from the successful experiences of foreign countries, and should make NFC payment technical standards consistent with international standards .

Clear the subjects of the responsibility and the principle of imputation of NFC payment. In the light of the existing laws and regulations, the subjects of liability should be clearly defined. At the same time, in line with the principle of protecting the legitimate rights of consumers, the principle of liability for tort liability be determined.

Certification of NFC payment means that the quality of the mobile terminal, technical indicators and operational standards must be approved by the state administrative organs and professional institutions witch have the credibility, and then could enter the NFC payment market. Among them, the most important is to clear certification bodies, certification content and legal consequences about the certification act.

Authorized of NFC payment means that in the subcontract production and distribution process of NFC chips or mobile terminal equipments, industry chain participants should choose certified units, and make clear its authorized scope and limits. The authorization of NFC payment shall include: first, the authorized business scope; second, clear rights restrictions; third, a reasonable solution to the dispute and the standard of responsibility. More importantly, the insurance services should be introduced in the authorization. Choose the right and authoritative insurance companies to provide risk insurance for NFC payment, so as to protect the legitimate rights and interests of the users.

In short, legal risk prevention should be systematic and normative . At the same time, the scope of participation of risk prevention should be expanded, including not only the administrative organs, financial institutions, industry chain participants, but also the certification authorities and the authorized units witch are professional and credible. 


\subsection{Regularize the utilization and protection of information}

Banks, operators and manufacturers to obtain the user's personal information and payment information is mainly aimed at analyzing the user's consumer behavior through big data. Through these analysis results to adjust the direction of future business development, in addition, can also be based on user behavior preferences, push related services business. But in the rational use of information at the same time, should guard against information leakage.

Strengthen information protection legislation, improve the NFC payment information protection laws and regulations. First, the introduction of the use and protection of user information management regulations, the formation of the system specification. Secondly, taking the rules for the use and protection of NFC payment information rules into the existing laws and regulations of the system.

The judicial department should understand the industry policy flexibly in practice. The judicial department shall deal with the NFC payment information disclosure case in an innovative and open manner, and take the excellent trial book as a guiding case.

Through strict enforcement of law to promote the NFC mobile payment industry self-regulation. The administrative supervision departments should uphold the principle of protecting the legitimate rights and interests of consumers, and strictly enforce the law. And encourage and help the NFC payment industry to establish a sound information protection system. Through these acts from the source to control the risk of leakage of information

\section{Summary}

The vigorous development of mobile e-commerce, not only changed the way of trading and consumer behavior, but also changed the development of electronic payment services, especially NFC pay rise, will promote the rapid development of mobile payment market. But there's no denying NFC payment is a double-edged sword, it liberates the entity credit card but at the same time it also bring many risks. Based on the mobile e-commerce model, in view of the risk of NFC payment putting forward relevant legal advice to promote the healthy development of NFC payment. To achieve the German "business daily" predicted that the China Mobile payment service will end the era of cash.

\section{${ }^{*}$ Key project of science and technology innovation fund for graduate students of Yantai University: 《Research on legal risks of mobile payment in the environment of mobile e-commerce》}

\section{References}

[1] Song Fengxuan ,Fan Jin, et al. Research on the Third Party Payment Risk Supervision Measures on Internet--Based on the Perspective of Government Regulation and Industry Self-regulation. Economic Forum. 2016.6(6)

[2] Sun Furong,et al. Leading the Global Payment Industry Innovation--an Interview with Ai Ruiqi, Vice President of VISA Company. China Finance. 2016(12)

[3] She Yunfeng, et al. The Current Situation and Development Analysis of the Development Trend of NFC from the Perspective of Data. NFC Industry Network.Information on:http://www.nfcin.com.cn/news.asp?apply=1

[4] Li jie, et al. Application Status and Prospects of Mobile Payments Dilemma. Network Security Technology\&Application. 2014

[5] Ou Yangbingyan et al. Application of NFC Technology in Mobile Payment. Guangdong Communication Technology. 2016.6 